\title{
MODALIDADE DE FOMENTO À PESQUISA NA ÁREA ASSISTENCIAL*
}

Rosa Áurea Quintella Fernandes 1

Sandra Honorato da Silva ${ }^{2}$

RESUMO:O trabalho apresenta a Organização do Comitê de Pesquisa Operacional em Enfermagem implantado no Departamento doHospital Universitário daUniversidade de São Paulo em 1993, com o objetivo de estimular, orientar e oferecer apoio logístico aos enfermeiros assistenciais, no desenvolvimento de pesquisas etrabalhos científicos. Relata, ainda, as estratégias adotadas para fomentar a pesquisa entre os enfermeiros e garantiro êxitos da proposta.

UNITERMOS - Pesquisa - Pesquisa Operacional - Hospitais Univèrsitários

\section{INTRODUÇÃO}

A importância da pesquisa como plataforma para o desenvolvimento de um corpo de conhecimentos específicos da enfermagem é assunto de publicações há pelo menos duas décadas. ${ }^{(7,15)}$

A revisão bibliográfica sobre a matéria permite visualizar a preocupação das lideranças de enfermagem do país, em incentivar e estimularos enfermeirosna elaboração detrabalhoscientíficos e introduzí-los no universo da pesquisa. $(1,2,4,5,12,15)$

CARVALHO ${ }^{(7)}$, em 1975, já apontava a premência da pesquisa na área da enfermagem, a necessidade de preparar as enfermeiras para esta atividade equestionava a escassez de enfermeiros pesquisadores. Diversos outros autores apresentam e discutem os fatores limitantes da pesquisa, sobretudo para os enfermeiros assistenciais ${ }^{(5,7,8,12)}$.

A retrospectiva histórica dos caminhos percorridos pelos enfermeiros em termos de pesquisa, demonstra que, apesar do avanço impulsionado sobretudo pela criação dos cursos de pós-graduação na década de 70 , referida por diversos autores $(1,2,3,6,9,12)$, a produção científica dos enfermeiros ainda pode ser considerada incipiente.

Autores que analisam a produção científica na enfermagem, enfatizam que, no Brasil, os pesquisadores de enfermagem concentram-se na área docente, e que desenvolvem suas pesquisas, na maioria das vezes, impulsionados por obrigações acadêmicas ${ }^{(2,4,8)}$, aspecto que tem contribuído para que as pesquisas se distanciem da realidade e das necessidades da prática assistencial .

Por outro lado, a tradição do desenvolvimento de pesquisa pelos enfermeiros docentes, cria uma aura de mitificação da pesquisa, que retrai o enfermeiro assistencial, afastando-o cada vez mais desta atividade.

CIANCIARULLO \& SALZANO(8) afirmam que o distanciamento dos enfermeiros assistenciais da pesquisa, constitui um paradoxo para aqueles que estudam a pesquisa articulada à prática, na busca de novas formas de fazer e conhecera essência da enfermagem.

Muito já se escreveu e analisou sobre os óbices do não engajamento do enfermeiro assistencial na pesquisa, podendo a baixa produção científica da área assistencial estar associada, principalmente, adoisfatores apontados pelos enfermeiros, quais sejam: a falta de conhecimento da metodologia de pesquisa e a inexistência de estrutura que favoreça o desenvolvimento da pesquisa nas instituições de saúde ${ }^{(11,13)}$.

\footnotetext{
Trabalho apresentado como Tema Livre no $46^{\circ}$ Congresso Brasileiro de Enfermagem. Prêmio Laís Neto dos Reys, $1^{\circ}$ lugar. Porto Alegre, 30 de outubro a 4 de novembro de 1994.

Doutora em Enfermagem pela Escola Enfermagem da Universidade de Sáo Paulo. Coordenadora do Comitê de Pesquisa Operacional do Hospital Universitário da Universidade de Sáo Paulo.

Doutoranda en Enfermagem pela Escola Enfermagem da Universidade de Sáo Paulo. Professora assistente da EEUSP

Diretora do Departamento de Enfermagem da Universidade de Săo Paulo.
}

e 
A análise desta problemática permite verificar que no âmbito da responsabilidade dos órgãos formadores, a questão vem sendo trabalhada, considerando que as escolạs de graduação em enfermagem do pais, vêm inserindo na grade curricular a disciplina "metodologia de pesquisa", e incentivando a participação dos graduandos nos projetos que of erecembolsas de iniciação científica à pesquisa.

No âmbito das instituições de saúde, a atividade do enfermeiro como pesquisador encontra-se ainda em fase de latência, demandando reflexão e amadurecimento.

Reconhece-se a iniciativa e o esforço de algumas instituições, em incentivar e oferecer oportunidades de crescimento aos enfermeiros assistenciais no campo da pesquisa. Entretanto, esta iniciativa depende exclusivamente da abrangência de visão das chefias, não refletindo um compromisso formal das instituições com a pesquisa.

Demaneirageral, a visão do papeldo enfermeiro assistencial como pesquisador não está incorporada, nem por ele ou seus parceiros, nem pelas chefias de enfermagem e muito menos pelo staff das instituições hospitalares. Essa realidade pode ser facilmente constatada pelo posicionamento destes elementos em relação à pesquisa e endossados pelos trabalhos de CARVALHO ${ }^{(7)}$, BURLAMAQUE ${ }^{(5)}$, LOPES(11), CIANCIRULLO \& SALZANO(8).

O desenvolvimento de pesquisas por enfermeiros assistenciais está vinculado, na maioriadas vezes, a parcerias com docentes nos projetos de integração docente-assistencial, e não tem demonstrado um caráter contínuo e sistemático. Tampouco tem sido introjetado, como parte constante, específica e inserida no rol de suas atividades profissionais.

Considerando os aspectos apontados, podese afirmar que uma causalidade de ação reciproca mantém a condição de alijamento do enfermeiro assistencial do desenvolvimento e engajamento com a pesquisa, podendo ser assim representada:

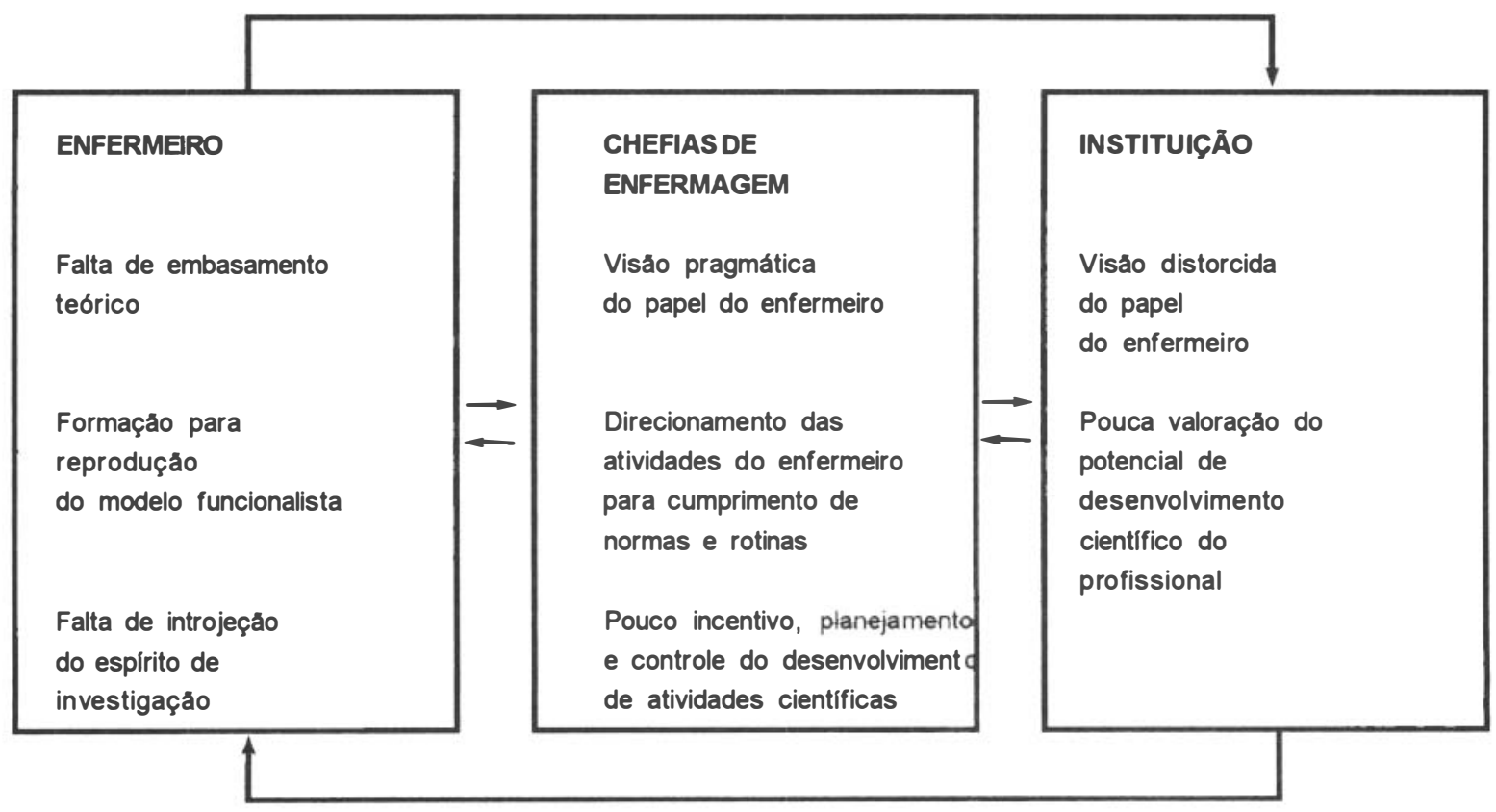

É importante salientar que outras variáveis podem estarenvolvidasneste processo, interagindo e aumentando sua complexidade. No entanto, os hospitais universitários devem romper estas barreiras e comprometer-se com sua parcela de responsabilidade no desenvolvimento da pesquisa na área de enfermagem.

Observa-sequeos enfermeiros, a o procurarem os hospitais universitários para o exercício da profissão, visualizam fundamentalmente 0 atendimento de suas expectativas de desenvolvimento e crescimento científico. 
A possibilidade de desenvolver pesquisas, assim como, conhecer e utilizar os resultados de experimentos realizados, além de incentivar os profissionais, pode favorecer o alcance da satisfação no trabalho.

Tal panorama acentua a responsabilidade das chefias de enfermagem dessas instituições, em criar uma infra-estrutura capaz de propiciar aos enfermeiros condições efetivas de uma prática diária desenvolvida numa ótica de investigação.

$\mathrm{KIM}{ }^{(10)}$ enfatiza que através da pesquisa, os enfermeiros poderão contribuir substancialmente para a saúde da população em termos de eficiência econômica, e melhoria da qualidade do cuidado, tornando a enfermagem no próximo século, uma profissão viável e respeitada academicamente.

\section{DESENVOLVIMENTO DA PESQUISA NO HOSPITAL UNIVERSITÁRIO DA UNIVERSIDADEDESÃOPAULO}

A visão de vanguarda que sempre caracterizou - Departamento de Enfermagem do Hospital Universitário da Universidade de São Paulo, e seu compromisso com a qualidade da assistência e com o desenvolvimento de seus profissionais, permitiu a criação de um polo catalisador de pesquisa na área de enfermagem.

ADiretoria do Departamento de Enfermagem acredita que os hospitais universitários devem constituir núcleos de excelência na área de investigação científica, e que a pesquisa deve fazer parte das atividades diárias do enfermeiro, tendo em vista a vocação de assistência, ensino e pesquisa, explicitada regimentalmente por esses hospitais.

A pesquisa como atividade do enfermeiro vem sendo estimulada e desenvolvida desde a implantação do hospital, vinculada ao projeto de integração docente-assistencial da Escola de Enfermagem e do Hospital Universitário da Universidade de São Paulo. No entanto, com vistas a ampliar a possibilidade de engajamento de todos os enfermeiros no desenvolvimento de trabalhos científicos, foi criado o Comitê de Pesquisa Operacional em Enfermagem.

O objetivo primordial do Comitê é estimular, orientar e oferecer apoio técnico e logístico aos enfermeiros do Departamento no desenvolvimento de pesquisas e trabalhos científicos. Foram definidas, juntamente com o Departamento de Enfermagem, três linhas de pesquisa, objetivando o aprofundamento das questões relativas à prática assistencial de enfermagem da instituição.

OComitêé coordenado porum enfermeiro com título de doutor, que dedica sua carga horária (36 horas semanais) exclusiva e integralmente ao desenvolvimento dostrabalhosna instituição. Além disso dispõe de área física própria, onde pode reunir os enfermeiros em pequenos grupos ou recebê-los individualmente para orientação. A estruturação do Comitê está descrita em regimento interno específico (ANEXO I).

Considerando que a prática assistencial, tanto em seus aspectos técnicos, quanto administrativos, tende a reproduzir-se num contexto de aderência inflexivel às ações pragmáticas e reiterativas, a criação do Comitê, por si só, não representaria fomento à pesquisa, demandando a adoção de estratégias complementaresparagarantiadoêxito da proposta.

As estratégias adotadas paralelamente à criação do Comitê, referem-se a:

reqrganização das atividades desenvolvidas pelo enfermeiro;

formação grupos de discussão e reflexão; incentivo a leituras científicas;

cursos de metodologia de pesquisa;

reuniões científicas;

divulgação dos trabalhos científicos;

incentivo ao ingresso dos enfermeiros em

cursos de pós-graduação e participação em eventos.

A reorganização das atividades diárias desenvolvidas pelo enfermeiro é fundamental, possibilitando a criação de espaços no cotidiano de sua atuação, de forma a contemplar o desenvolvimento da pesquisa. Para tanto, estas atividades foram analisadas e revisadas, excluindose aquelas de caráter rotineiro e burocrático que consumem otempo deste profissional, e passíveis de rf alização por outros elementos da equipe de enfermagem, sem comprometimento para a qualidade assistencial.

Osgrupos de discussão e reflexão representam a essência do processo, considerando-se a importância de sensibilizar os profissionais para a mudança de paradigma do papel do enfermeiro assistencial, de modo a incorporar a investigação como componente indispensável para a consecução de suas atividades, e fundamentação de uma prática assistencial.

Visando tornar o enfermeiro assistencial um assíduo consumidor da literatura científica 
conforme recomendam TREVISAN\& MENDES ${ }^{(17)}$ e AUGUSTO(2) , são planejados claros em suas atividades a serem preenchidos com tempo de biblioteca, programados em escala mensal, objetivando a realização de levantamento bibliográfico e formação de acervo de artigos com assuntos de interesse da unidade. Tal estratégia, possibilita manter os enfermeiros atualizados em relação aos aspectos concernentes à assistência, despertando-os e incentivando-os para o hábito da leitura crítica de textos científicos.

O planejamento do referencial bibliográfico, que atenda às especificidades da atividade de enfermagemdesenvolvidanaunidade, deveenvolver todo o grupo de enfermeiros, favorecendo o engajamento e a efetividade da proposta.

O oferecimento de cursos de metodologia de pesquisa é outra estratégia de vital importância, no sentido de tornar os enfermeiros preparados para o início de suas atividades de pesquisa. Tais cursos, além de oferecer o embasamento teórico necessário, promovem momentos de ensaios práticos para aplicação dos tópicos abordados. 0 conteúdo programático dos primeiros cursos teve um enfoque basicamente quantitativo, com pequenos espaços dedicados aos aspectos qualitativos de pesquisa. BOEMER ${ }^{(4)}$, na avaliação de experiência semelhante, ressalta a propriedade de iniciar o preparo dos enfermeiros pelo método positivista.

As alternativas metodológicas com enfoque qualitativo serão abordadas em etapas subseqüentes, quando o grupo demostrar amadurecimento.

As reuniões científicas atuam como forma de divulgação e discussão dos resultados de pesquisa e suas implicações para a prática assistencial. Para a realização destas reuniões, são convidados especialistas e selecionados temas de interesse, visando o desenvolvimento cognitivo e fundamentação para a transformação das ações assistenciais e administrativas. Essas reuniões são programadas de forma a prever a participação do profissional durante sua jornada de trabalho.

Acredita-se que esta estratégia, além de beneficiar os enfermeiros assistenciais, abre um campo para o pesquisador, que tem oportunidade de divulgar e operacionalizar efetivamente os resultados de sua investigação.

A divulgação de trabalhos científicos e pesquisas é tão importante quanto produzí-los. STEFANELLI (16) afirma que os enfermeiros assistenciais, muitas vezes desenvolvem ricos trabalhos de pesquisa, mas não chegam a divulgálos.

O Comitê de Pesquisa preocupa-se com esta questão, e procurautilizarestratégiasde divulgação interna e externa dos trabalhos produzidos.

A divulgação interna ocorre nas reuniões científicas mensais, em eventos como Semana da Enfermagem e pelo informativo do Departamento deEnfermagem. A divulgação extema é estimulada pela apresentação de trabalhos em eventos e pela publicação em periódicos nacionais e intemacionais.

OHospital Universitário conta com uma revista trimestral, que dá suporte e garante espaço para a divulgação da produção interna dos enfermeiros.

O Boletim Informativo, criado pelo Departamento deEnfermagem, representa mais uma estratégia direcionada para a motivação dos enfermeiros, pois permite divulgar os trabalhos elaborados, de forma que o conhecimento da produção do grupo se extenda a todas as áreas da instituição. KIM ${ }^{(10)}$ e STYLES ${ }^{(14)}$ colocam que os resultados das pesquisas devem ser disseminados a todos os setores, inclusive para a sociedade, como fonte de reconhecimento da importância e capacidade do enfermeiro de intervirnos problemas de saúde da população e contribuir para sua solução.

Finalmente, no elenco das estratégias situase 0 estímulo ao ingresso de enfermeiros assistenciais em cursos de pós-graduação, aspecto de extrema relevância, quando se considera a necessidade de existir, nas instituições hospitalares, enfermeiros preparados para intervirem natransformação da prática assistencial. Esses enfermeiros atuarão como elementos multiplicadores do conhecimento e integrarão. quando preparados, o Comitê na qualidade de orientadores.

O incentivo ao ingresso em tais cursos, ocorre com o estabelecimento de condições que viabilizam a continuidade do trabalho dos enfermeiros na instituição e o desenvolvimento do programa de pós-graduação.

\section{CONSIDERAÇÕES FINAIS}

A modalidade de fomento à pesquisa desenvolvida no Hospital Universitário da Universidade de São Paulo, embora recente, vislumbra um panorama e de efetivo engajamento 
dos enfermeiros na pesquisa.

Esta experiênciadeve serimplantada por outras instituiçōes, pois a enfermagem deve mobilizar-se e fortalecer-se em pesquisa, considerando que a responsabilidade da construção do saberdeve ser compartilhada por todos os profissionais.
O CIE tem recomendado e estabelecido a pesquisa como prioridade para a enfermagem em todo o mundo.

O fundamental éque toda ação, seja uma ação reflexiva e calcada na investigação científica.

ABSTRACT: This paperdeals with the organization of the Operational Research Committee implemented at the University Hospital of the University of São Paulo in 1993 with the objective of giving logistic support to nurses in the development of their scientific work. It shows the strategies adopted to encourage research among nurses to reach the success of the proposal.

KEYWORDS: Research-Operational Research-Hospitals, university.

\section{REFERÊNCIAS BIBLIOGRÁFICAS}

1- ANGERAMI, E.L.S. O mister da investigaçăo do enfermeiro. Rev.Lat.Am.Enf., Ribeirăo Preto, v.1, n.1, p.11-22, jan. 1993.

2- AUGUSTO, M.A. A importăncia da pesquisa em enfermagem. Rev.Acta Paul. Enf., Sáo Paulo, v.3, p.103-5, set. 1990.

3- BARREIRA, I. de A. A pesquisa em enfermagem no Brasil e

sua posiçăo em agência federal de fomento. Rev. Lat. Am. Enf. Ribeiråo Preto, v.1, n.1, p.51-57, jan. 1993.

4 BOEMER, M.R. et al. Proposta alternativa para a produçăo cientifica de enfermeiros assistenciais. Rev. Enf., USP, Săo Paulo, v.24, n.2, p.211-223, ago. 1990.

5- BURLAMAQUE, C.S., BECKER, M.M.F., LUZ, A.N.H Avaliação da produçáo científica dos enfermeiros do Rio Grande do Sul. Rev. Gaúcha Enf., Porto Alegre, v.7, n.2, p.157-179, jun. 1989.

6. CAMARGO, A.P.S. et al. Situaçăo da produçăo cientifica em enfermagem no estado de Santa Catarina. Rev. Gaúcha Enf. Porto Alegre v.7, n.2, p.180-198, jul. 1986.

7- CARVALHO, A.C. Como utilizar a pesquisa para melhor orientar a açăo da enfermagem. Rev. Esc. Enf. da USP., Săo Paulo, v.9, n.1, p.20-6, abr. 1975.

8- CIANCIARULLO, T. I. \& SALZANO, S.T. A enfermagem e a pesquisa no Brasil . Rev. Esc. Enf. USP., Sảo Paulo, v.25, n.2, p.195-215, ago. 1991.

9- FREITAS, D.M.V., RUFFINO, M.C., SAEKI, T. A produçáo cientifica do enfermeiro no Estado de Săo Paulo no triênio 1985-1988. Rev. Paul. Enf., Săo Paulo, v.11, n.3, p.123-129, set/dez. 1992.
10- KIM, M.I. Nursing rescarch: a wordwide picture. Rev. Esc. Enf. USP, Såo Paulo, v.26, p. 7-22, out. 1992, número especial.

11- LOPES, C.M. Pesquisar pra assistir. Rev. Esc. Enf. USP., Săo Paulo, v.26, p.7-22, out. 1992, número especial.

12-NOGUEIRA, M.J.C. A pesquisa em enfermagem no Brasil: retrospectiva histórica. Rev. Esc. Enf. USP., Săo Paulo, v.16, n.1, p.7-26, abr. 1982.

13- SILVA, C.M. da, et al. Pesquisa em enfermagem: importáncia e sua evoluçăo no Brasil. Rev. Acta Paul. Enf., Săo Paulo, v.4, n.1, p. 34-38, mar. 1991.

14- STYLES, M.M. Empowering nursing research and nursing Mresearchers. Rev. Esc. Enf. USP., Sáo Paulo, v. 26, p.23-32, outubro 1992, número especial.

15- SOUZA. M.F. \& GUTIERREZ, M.C.R. Pesquisa em enfermagem. Rev.Acta Paul. Enf., v.3, n.4, p.137-142, dez. 1990.

16- STEFANELLI, M. Enfermeiras assistenciais e produçáo cientifica. Rev. Paul. Enf., Såo Paulo, v.9, n.3, set./dez. 1990.

17- TREVISAN, M.A. \& MENDES, I.A.C. Iniciaçâo cientifica: modalidade de incentivo à pesquisa em enfermagem. Rev. Gaúcha de Enf. , Porto Alegre, v.12, n.2, p.3-38, jul. 1991.

Recebido para publicaçăo em 4/11/94. Aprovado para publicaçáo em 4/2/95. 

(C.P.O.E)

\section{CAPITULOI \\ DAS FINALIDADES}

Art. $1^{\circ}$-O Comitê de Pesquisa Operacional em Enfermagem (C.P.O.E) tem por finalidade:

I- Contribuir para o crescimento e consolidação da ciência enfermagem.

II- Estabelecerjuntamente com a Diretoria do Departamento de Enfermagem, suas linhas de pesquisa.

III-Estimular a produção científica dos enfermeiros do Departamento de Enfermagem (D.E.). IV-Orientar os trabalhos científicos, elaborados pelos enfermeiros do Departamento de Enfermagem.

V- Coordenar a participação dos enfermeiros do Departamento de Enfermagem em Congressos, Jornadas, Palestras e outros, quando houver apresentação de trabalho.

VI-Promover e coordenar cursos pertinentes à área.

VII- Oferecer infra-estrutura e apoio logístico para a elaboração de trabalhos.

\section{CAPITULO II \\ DASUBORDINAÇÃO}

Art $2^{\circ}$ - O Comitê de Pesquisa Operacional em Enfermagem, está diretamente subordinado ao Departamento de Enfermagem.

\section{CAPITULOIII \\ DA DIREÇÃO}

Art $3^{\circ}$ - - O Comitê de Pesquisa Operacional em Enfermagem, será coordenado por um enfermeiro, com título mínimo de doutor.

\section{CAPÍTULOIV \\ DA COMPOSIÇÃO}

Art 4 - O Comitê de Pesquisa Operacional em Enfermagem será composto por:

I-Um Coordenador

II-Orientadores

III-Secretária

Parágrafo $1^{\circ}$ - Os orientadores de trabalhos científicos deverãoter otítulo mínimo de mestre. Parágrafo $2^{\circ}$ - Os orientadores deverão ser enfermeiros vinculados ao Hospital Universitário ou docentes da Escola de Enfermagem da USP.

Inciso Único: - Excepcionalmente outros enfermeiros titulados poderão orientartrabalhos realizadosporenfermeiros do Hospital Universitário, desde que autorizados pelo Departamento de Enfermagem e Comitê de Pesquisa Operacional em Enfermagem.

\section{CAPÍTULOV \\ DOS TRABALHOS}

Art. $5^{\circ}$ - Os trabalhos de pesquisa em enfermagem serão desenvolvidos pelos enfermeiros Iotados no Departamento de Enfermagem.

Páragrafo $1^{\circ}$ - Todo enfermeiro poderá e deverá desenvolver trabalho de pesquisa. 
Páragrafo $2^{\circ}$ - Nenhum enfermeiro poderá desenvolver e/ou apresentartrabalhos científicos realizados no Hospital Universitário, sem observar as normas estabelecidas.

Páragrafo $3^{\circ}$ - Nenhum trabalho poderá ser desenvolvido sem a apresentação prévia do plano de pesquisa, ao Comitê de Pesquisa Operacional em Enfermagem.

Inciso Único - Os trabalhos por docente da EEUSP deverão ter o plano de pesquisa encaminhado ao C.P.O.E., assim como o trabalho final, objetivando registro e arquivo, não competindo ao C.P.O.E. análise e acompanhamento dos mesmos.

\section{CAPITULOVI \\ DACOMPETÊNCIA}

Art. $6^{\circ}$ - Compete ao Coordenadordo Comitê de Pesquisa Operacional em enfermagem: I - Coordenar todos o strabalhos ligados à pesquisa, realizados por enfermeiros docentes ou assistenciais, no âmbito do Hospital Universitário.

II- Coordenar as reuniões científicas do Comitê.

III - Manter entrosamento e encaminhar à CEP os projetos de pesquisa a serem desenvolvidos porenfermeiros.

IV - Apresentar a Diretoria do Departamento de enfermagem, mensalmente, relatório de atividades e produção científica do Comitê de Pesquisa Operacional em Enfermagem;

$V$-Manter entrosamento com Biblioteca e Centro de processamento de Dados do Hospital Universitários e outras instituições.

$\mathrm{VI}$ - Orientar trabalhos de pesquisa.

VII - realizar Projetos Interligados de Pesquisa.

VIII - Captar recursos junto a órgãos financiadores de pesquisa.

IX-Manter entrosamento com demais orientadores e acompanhar desenvolvimento dos trabalhos não orientados por docentes.

Art $7^{\circ}$ - Compete aos orientadores:

I-Orientar os enfermeiros assistenciais na elaboraçãodosplanos e no desenvolvimento de trabalhos de pesquisa.

II - Encaminhar os planos de pesquisa ao C.P.O.E.

III - Estabelecer juntamente com o Coordenador do Comitê de Pesquisa Operacional em Enfermagem, o cronogramadostrabalhos em andamento, excetuando-se os orientados por docente.

IV - Colaborar no desenvolvimento de cursos e reuniões científicas ligadas a área.

\section{CAPÍTULOVII DAS DISPOSIÇÕES GERAIS}

$\mathrm{Art}^{\circ} 8^{\circ}$ - Nenhum trabalho científico poderá ser realizado por enfermeiro no âmbito do . Hospital Universitário, sem o conhecimento do Comitê de Pesquisa Operacional em Enfermagem.

Art $9^{\circ}$ - Nenhum trabalho científico poderá ser apresentado em Congresso, Jornada e outros, por enfẹrmeiro do Hospital Universitário, sem a aprovação do Comitê de Pesquisa Operacional emEnfermagem, exceto os vinculados aos programas de pós-graduação da EEUSP.

Art. $10^{\circ}$ - O Comitê de Pesquisa Operacional em Enfermagem ficará responsável pela divulgação e publicação dos trabalhos em periódicos. 